\title{
Pelatihan TOEFL secara virtual bagi anggota Nasyiatul 'Aisyiah Cabang Mantrijeron Yogyakarta
}

\author{
Luluk Iswati \\ Program Studi Manajemen, Fakultas Ekonomi dan Bisnis \\ Universitas Muhammadiyah Yogyakarta \\ Email Korespondensi: luluk007@umy.ac.id
}

Received May 12, 2021; Revised May 26, 2021; Accepted May 27, 2021

\begin{abstract}
Abstrak
Penguasaan dan kesiapan dalam menghadapi tes TOEFL merupakan hal penting karena tes ini dipakai untuk berbagai macam tujuan seperti syarat untuk menyelesaikan studi, melamar pekerjaan, promosi jabatan, dan melanjutkan pendidikan. Oleh karena itu, perlu diadakan pelatihan untuk menyiapkan diri menghadapi tes TOEFL terutama bagi para anggota Nasyiatul 'Aisyiyah (NA) Cabang Mantrijeron Yogyakarta. Hal ini dikarenakan kemampuan para anggota NA Mantrijeron dalam menghadapi tes TOEFL masih perlu ditingkatkan, terutama sebagai syarat untuk menyelesaikan studi, melamar pekerjaan, promosi jabatan, maupun melanjutkan pendidikan. Pelatihan TOEFL ini diadakan secara virtual melalui Google Meet dengan frekuensi 3 kali seminggu dan total 8 sesi/@60 menit. Evaluasi di akhir program pelatihan yang dilakukan melalui Google Form menghasilkan beberapa temuan penting yaitu: kendala dalam mengikuti pelatihan secara penuh karena jadwal bersamaan dengan kegiatan lain, durasi pelatihan dirasa cukup, jumlah sesi pelatihan dirasa kurang, peserta mendapatkan cukup banyak pengetahuan, penjelasan instruktur dapat diterima dengan baik, peserta mampu menyerap materi dengan baik, dan kepercayaan diri peserta terhadap TOEFL meningkat. Berdasarkan temuan tersebut dapat disimpulkan bahwa pelatihan TOEFL bagi anggota NA Mantrijeron Yogyakarta bermanfaat untuk menyiapkan mereka dalam menghadapi tes TOEFL untuk tujuan mereka masing-masing.
\end{abstract}

Kata Kunci: pelatihan TOEFL; Virtual; Nasyiatul 'Aisyiyah Mantrijeron

\section{Abstract}

Mastery and readiness in facing the TOEFL test are important because this test is used for various purposes such as requirements for completing studies, applying for jobs, promotion, and continuing education. Therefore, it is necessary to hold training to prepare for the TOEFL test, especially for members of Nasyiatul 'Aisyiyah (NA) Yogyakarta Mantrijeron Branch. This is because the ability of NA Mantrijeron members in facing the TOEFL test still needs to be improved, especially as a condition for completing studies, applying for jobs, promotion of positions, or continuing education. The TOEFL training is held virtually through Google Meet with a frequency of 3 times a week and a total of 8 sessions / @ 60 minutes. The evaluation at the end of the training program carried out through Google Form produced several important findings, namely: constraints in participating in the full training because the schedule was concurrent with other activities, the duration of the training was deemed sufficient, the number of training sessions was deemed insufficient, participants gained quite a lot of knowledge, the instructor's explanation was acceptable well, participants are able to absorb the material well, and their confidence in TOEFL increases. Based on these findings, it can be concluded that the TOEFL training for NA Mantrijeron Yogyakarta members is useful for preparing them for the TOEFL test for their respective goals.

Keywords : TOEFL training,; Virtual; Nasyiatul 'Aisyiyah Mantrijeron

\section{PENDAHULUAN}

Test of English as a Foreign Language (TOEFL) merupakan salah satu alat ukur kompetensi Bahasa Inggris bagi non-penutur asli yang paling banyak digunakan. Saat ini, sertifikat TOEFL semakin banyak digunakan untuk berbagai tujuan, diantaranya yaitu: persyaratan kelulusan studi di perguruan tinggi, prasyarat untuk melamar pekerjaan di berbagai instansi, melanjutkan studi ke jenjang yang lebih tinggi, melamar beasiswa, dan promosi jabatan [1]. Oleh karena itu, kebutuhan untuk mencapai skor TOEFL yang memadahi menjadi hal penting, walaupun untuk banyak orang tidak mudah untuk mencapai skor yang diharapkan [1] [2]. Salah satu upaya yang bisa dilakukan untuk membekali mereka yang membutuhkan skor TOEFL adalah melalui pelatihan. Pada umumnya, pelatihan TOEFL mempersiapkan peserta agar lebih percaya diri sebelum menempuh tes TOEFL, karena melalui pelatihan mereka belajar tentang strategi ketika mengerjakan tes TOEFL. Selain itu, peserta yang mengikuti pelatihan TOEFL biasanya menjadi tidak asing dengan tipe-tipe soal yang diteskan. 
Nasyiatul 'Aisyiyah (NA) merupakan organisasi remaja putri dari salah satu organisasi otonom milik persyarikatan Muhammadiyah yang berdiri 16 Mei 1931. Nasyiatul 'Aisyiah tersebar di seluruh Indonesia termasuk di Yogyakarta. Salah satunya yaitu NA Cabang Mantrijeron Yogyakarta yang merupakan wadah berorganisasi bagi remaja putri Islam di wilayah kecamatan Mantrijeron, Yogyakarta. Anggota NA Mantrijeron saat ini berjumlah sekitar 30 orang dan mereka berstatus sebagai siswi SMA/MA, mahasiswi, dan juga karyawati. Berbagai kegiatan berorganisasi diadakan untuk membekali anggotanya agar menjadi generasi muda yang terampil, bertaqwa, dan bermanfaat bagi masyarakat. Kegiatan-kegiatan yang diadakan Pimpinan Cabang NA Mantrijeron bersifat rutin dan insidentil. Kegiatan rutin yang diadakan yaitu pengajian PCM Mantrijeron, musyawarah ranting, rapat pleno PCNA, dan Rapat PCM. Sedangkan kegiatan non-rutin sudah pernah diadakan oleh PCNA Mantrijeron yaitu dalam bentuk pelatihan jurnalistik, pelatihan administrasi, pelatihan public speaking, pelatihan program neuro linguistic, dan lain sebagainya.

Kegiatan pengabdian kepada masyarakat dalam bentuk pelatihan TOEFL banyak diberikan untuk berbagai kelompok masyarakat seperti dalam [1]-[7]. Hal ini menunjukkan bahwa TOEFL memang dibutuhkan oleh banyak kalangan masyarakat untuk berbagai keperluan baik dalam hal karir maupun akademik. Pandemi Covid-19 yang belum juga usai ini menyebabkan kegiatan pengabdian masyarakat banyak dilakukan secara virtual [8]. Terutama kegiatan pengabdian dalam bentuk pelatihan, pandemi ini memunculkan tantangan untuk menyelenggarakan pelatihan yang mau tidak mau harus dilakukan secara online [9] [10] [11]. Berbagai kegiatan pelatihan juga harus diselenggarakan secara virtual dengan memanfaatkan berbagai platform tidak berbayar maupun berbayar. Lingkungan online seperti aplikasi jejaring sosial, situs, dan dunia virtual telah menciptakan peluang bagi para pembelajar untuk saling berinteraksi dengan memberikan kesempatan secara online untuk saling melihat atau mengobrol satu sama lain kapan saja dan di mana saja [12].

Permasalahan yang dihadapi oleh para anggota NA Mantrijeron adalah masih diperlukannya peningkatan kemampuan dan kesiapan para anggota dalam menghadapi tes TOEFL. Kemampuan dalam menghadapi tes TOEFL penting bagi anggota NA Mantrijeron Yogyakarta agar menunjang kesuksesan studi dan karir mereka. Sedangkan selama ini, dalam organisasi mereka belum diadakan pelatihan TOEFL. Oleh karena itu, perlu diadakan pelatihan TOEFL bagi para anggota NA Mantrijeron. Dengan mendapatkan pelatihan TOEFL, maka para anggotanya diharapkan lebih percaya diri dan siap ketika harus menempuh tes TOEFL. anggota

\section{METODE}

a. Waktu

Kegiatan pengabdian kepada masyarakat dalam bentuk pelatihan TOEFL ini diadakan dalam kurun waktu bulan April-Mei 2021 sebanyak 8 sesi, dengan durasi per sesi selama 60 menit. Pelatihan ini bersifat semi intensif, yaitu diadakan sebanyak 3 kali dalam seminggu dengan jadwal setiap hari Selasa, Kamis, dan Sabtu pukul 16.00-17.00. Kegiatan ini diadakan untuk anggota Nasyiatul 'Aisyiyah Cabang Mantrijeron Yogyakarta yang berkantor di Kompleks Masjid Ngadinegaran, Jalan Panjaitan No.21 Yogyakarta.

b. Metode penyelesaian masalah

Dalam kegiatan pengabdian kepada masyarakat ini, untuk menyelesaikan permasalahan yang dihadapi oleh mitra , maka diberikan transfer ilmu pengetahuan dalam bentuk pelatihan TOEFL. Pelatihan ini diberikan agar kemampuan dan kesiapan anggota NA Mantrijeron dalam menghadapi TOEFL bisa meningkat, baik untuk tujuan akademik maupun karir mereka. Karena kegiatan pengabdian ini berlangsung di tengah pandemi Covid19, maka teknologi yang digunakan dalam pelaksanaan pelatihan yaitu Google Meet, yang memberikan fasilitas untuk berinteraksi dan melaksanakan pelatihan secara virtual. Google Meet dipilih karena mudah digunakan, tidak berbayar, semua peserta sudah memiliki akun email di Google, dan bisa mengakomodir durasi dalam tiap sesi pelatihan. Melalui Google Meet komunikasi dua arah secara virtual bisa terjalin dengan fasilitas audio dan kamera.

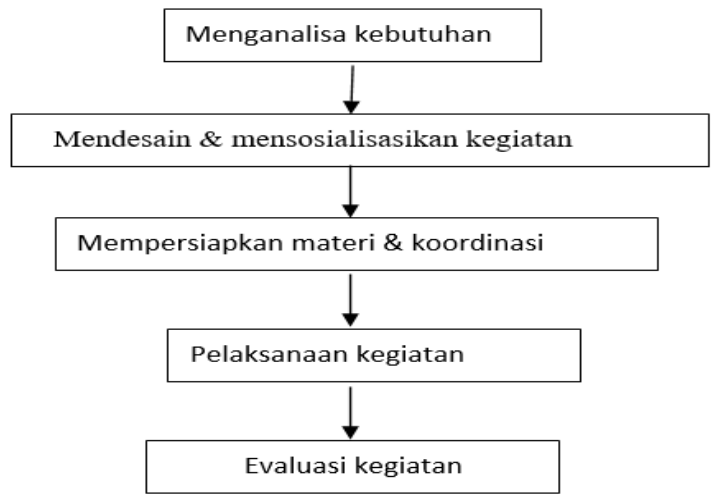

Gambar 1. Diagram alur kegiatan pelatihan TOEFL. 
c. Prosedur kegiatan

Kegiatan pengabdian kepada masyarakat dalam bentuk pelatihan TOEFL bagi anggota NA Mantrijeron Yogyakarta ini dilaksanakan dengan mengikuti langkah-langkah seperti yang digambarkan dalam diagram di gambar 1

Berdasarkan diagram di atas, langkah pertama yang dilakukan adalah menganalisa kebutuhan mitra yaitu menggali informasi tentang apa yang dibutuhkan bagi anggota NA Mantrijeron Yogyakarta. Setelah diperoleh informasi bahwa para anggota NA Mantrijeron Yogyakarta membutuhkan pelatihan TOEFL untuk mempersiapkan mereka dalam menghadapi tes TOEFL, maka tim pengabdian mendesain pelatihan. Jadwal yang sudah dirancang disosialisasikan kepada para anggota melalui grup WhatsApp yang sengaja dibentuk untuk keperluan kegiatan ini. Setelah itu, tim pengabdian merancang materi dengan merujuk pada [13]. Koordinasi kegiatan juga dilakukan dengan pengurus NA Mantrijeron Yogyakarta agar kegiatan berjalan sesuai yang direncanakan. Tahapan berikutnya yaitu pelaksanaan kegiatan sesuai dengan jadwal yang sudah disepakati oleh tim pengabdian dan pengurus NA Mantrijeron. Tahapan yang terakhir yaitu evaluasi kegiatan yang bertujuan untuk menjaring kesan, pendapat, serta masukan dari peserta kegiatan tentang pelatihan TOEFL yang mereka ikuti.

d. Teknik mengumpukan dan menganalisa data

Data yang digunakan dalam kegiatan pelatihan TOEFL ini diambil melalui Google Form yang dibagikan kepada peserta pelatihan melalui grup WhatsApp. Data memuat informasi tentang status pekerjaan peserta dan beberapa pertanyaan terkait pelatihan yang mereka ikuti. Data diambil setelah peserta selesai mengikuti pelatihan. Kemudian data dianalisa berdasarkan prosentase, lalu disajikan dengan pie chart dan dideskripsikan secara verbal.

\section{HASIL DAN PEMBAHASAN}

Kegiatan pelatihan TOEFL anggota NA Mantrijeron Yogyakarta diikuti oleh 38 peserta dengan status pekerjaan seperti ditunjukkan dalam diagram berikut ini:

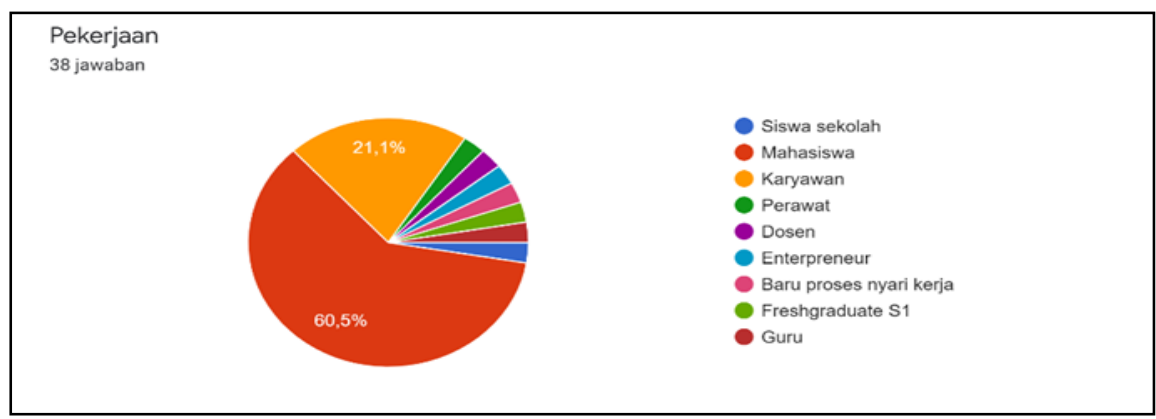

Gambar 2. Data status peserta

Seperti ditunjukkan dalam diagram di atas, 60,5\% atau sebanyak 23 peserta berstatus mahasiswa, kemudian diikuti oleh posisi sebanyak $21,1 \%$ kedua yaitu karyawan. Ini menunjukkan bahwa anggota NA Mantrijeron yang berstatus mahasiswa mempunyai minat paling tinggi untuk mengikuti kegiatan ini. Adapun jadwal dan distribusi materi pelatihan ditunjukkan dalam tabel berikut ini:

Tabel 1. Jadwal dan materi pelatihan TOEFL

\begin{tabular}{lll}
\hline Sesi & Hari/tanggal & Materi \\
\hline 1 & Sabtu/ 17 April 2021 & Introduction to TOEFL \\
2 & Selasa/20 April 2021 & Strategies and skills of listening part A: Skills 1 - 5 \\
3 & Kamis/22 April 2021 & Strategies and skills of listening part A: Skills 6-10 \\
4 & Sabtu/24 April 2021 & Strategies and skills of structure \& written expressions: Skills \\
& & $1-5$ \\
5 & Selasa/27 April 2021 & Strategies and skills of reading comprehension: Skills 1-5 \\
6 & Kamis/ 29 April 2021 & Strategies and skills of listening part B \\
7 & Sabtu/ 1 Mei 2021 & Strategies and skills of listening part C \\
8 & Selasa/ 4 Mei 2021 & Strategies and skills of structure \&written expressions: Skills \\
& & 6-15 \\
\hline
\end{tabular}

Tabel di atas menunjukkan bahwa materi pelatihan TOEFL yang diberikan mencakup tiga bagian yang diteskan dalam TOEFL yaitu listening comprehension, structure \& written expressions, dan reading 
comprehension. Dalam pelaksanaannya, karena jumlah sesi yang terbatas, maka tidak semua skill yang ada dalam tiap bagian bisa disampaikan. Bagian yang paling banyak dibahas yaitu listening comprehension, karena masih banyak peserta yang memerlukan latihan lebih banyak untuk mendengarkan penutur asing berbicara.

Karena kegiatan ini dilangsungkan di tengah masa pandemi Covid-19, maka pelatihan diadakan secara virtual dengan menggunakan platform Google Meet. Pertama-tama pengajar menyajikan penjelasan materi menggunakan power point slides yang dibagi melalui Google Meet, lalu setelah itu peserta diberikan latihan untuk menjawab beberapa soal dan mengecek pemahaman mereka terhadap materi yang diberikan. Pelatihan yang diberikan bersifat dua arah, dengan banyak melibatkan peserta untuk aktif menjawab dan bertanya, sehingga interaksi bisa berjalan dengan baik. Peserta menunjukkan perhatian yang serius ketika mengikuti pelatihan, yang ditandai dengan keaktifan mereka untuk menjawab soal-soal latihan. Hal ini sejalan dengan [14] yang menemukan bahwa dalam pelatihan TOEFL peserta memperlihatkan antusiasmenya.

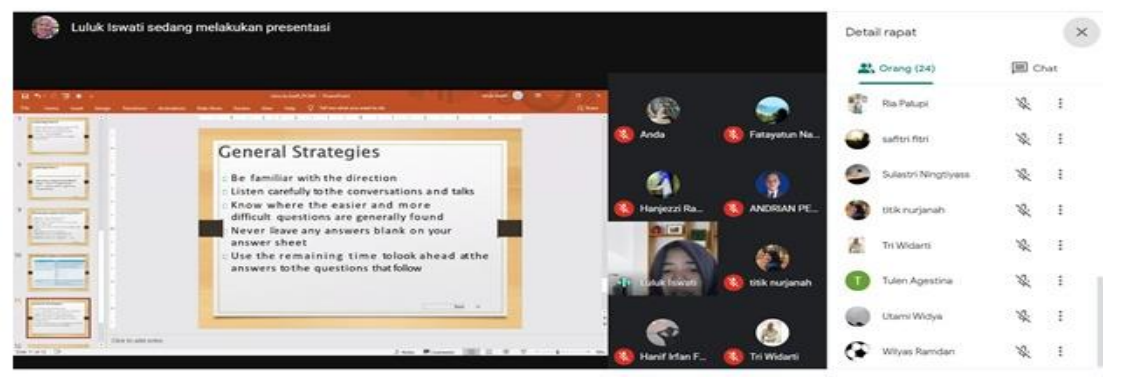

Gambar 3. Pelatihan TOEFL melalui Google Meet.

Selain menggunakan Google Meet, pengajar juga menggunakan grup WhatsApp untuk berbagi materi dalam bentuk soft file. Media WhatsApp juga digunakan untuk berkoordinasi, mengingatkan peserta untuk bergabung ke kelas, atau membagi alamat tautan kelas.

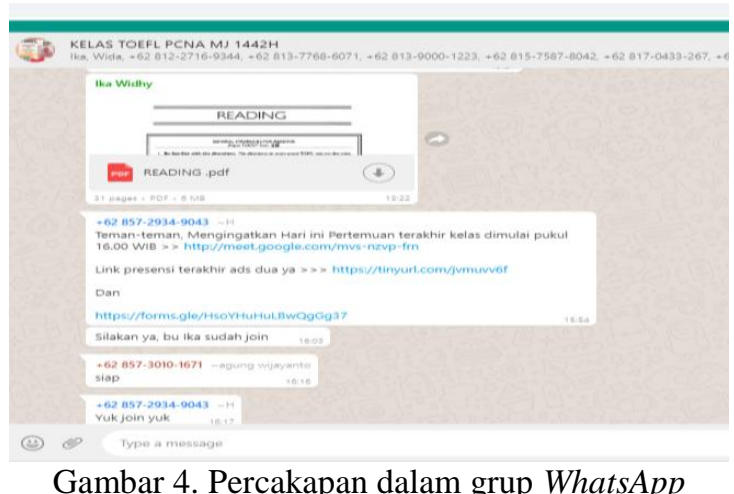

Setelah seluruh sesi pelatihan TOEFL dilaksanakan, tim pengabdian membagikan tautan Google Form untuk mengevalusi kegiatan. Dalam form tersebut para peserta diminta untuk menjawab beberapa pertanyaan.

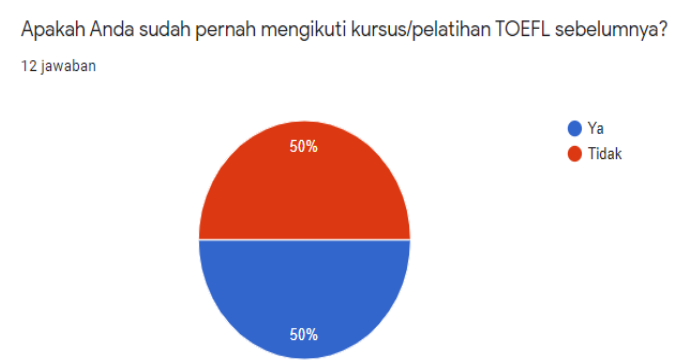

Gambar 5. Respon peserta tentang pelatihan TOEFl yang pernah diikuti.

Gambar 5 menunjukkan bahwa dari total peserta yang mengisi Google Form (12 peserta), jumlah yang pernah mengikuti pelatihan TOEFL sebelumnya sama banyaknya dengan jumlah peserta yang belum 
pernah mengikuti pelatihan TOEFL sebelumnya. Ini menunjukkan bahwa meskipun sebagian peserta pernah mendapatkan pelatihan TOEFL sebelumnya, mereka masih membutuhkan pelatihan lagi.

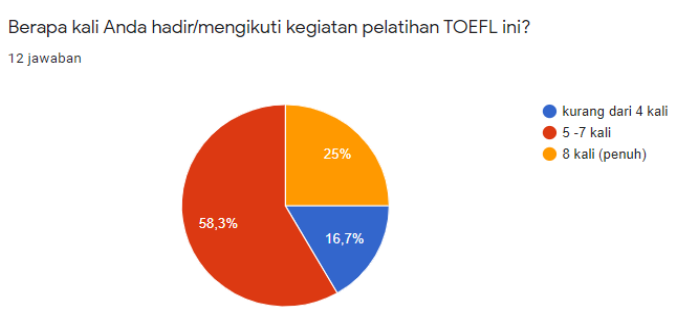

Gambar 6. Frekuensi keikutsertaan peserta dalam pelatihan TOEFL.

Dari 12 peserta yang mengisi Google Form seperti ditunjukkan pada Gambar 6, sebagian besar atau $58,3 \%$ mengikuti pelatihan sebanyak 5-7 kali, 25\% mengikuti pelatihan secara penuh, dan $16.7 \%$ mengikuti pelatihan kurang dari 4 kali. Fakta ini menarik untuk diungkap mengingat cukup sedikit yang mengikuti pertemuan sebanyak 8 sesi (secara penuh). Hal ini diungkap dalam data di bawah ini yang menjelaskan kendala yang dihadapi peserta yang berhubungan dengan frekuensi pelatihan yang bisa mereka ikuti.

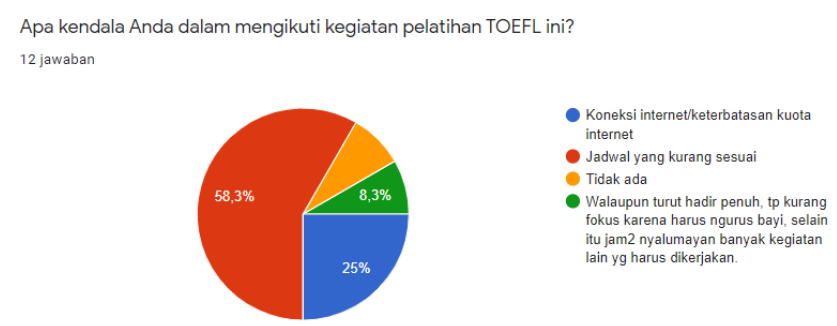

Gambar 7. Kendala peserta dalam mengikuti pelatihan TOEFL.

Gambar 7 menunjukkan data mengenai kendala peserta dalam mengikuti kegiatan pelatihan TOEFL. Sebagian besar atau $58.3 \%$ peserta mengaku bahwa jadwal yang ditentukan kurang sesuai, sehingga jumlah peserta yang mengikuti pelatihan di tiap sesinya tidak konsisten. Ketidaksesuaian jadwal yang berbenturan dengan kegiatan peserta menyebabkan mereka tidak bisa mengikuti pelatihan secara penuh. Ini sesuai dengan temuan [1]. Selain itu, cukup banyak peserta atau 25\% yang mengalami kendala koneksi internet atau keterbatasan kuota internet yang mereka miliki, sehingga mereka kurang optimal dalam mengikuti pelatihan. Koneksi internet menjadi salah satu masalah dalam pelaksanaan pembelajaran online [15][16]

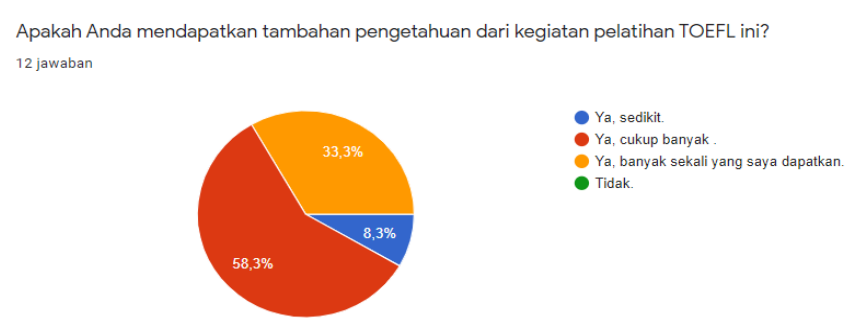

Gambar 8. Respon peserta tentang pengetahuan yang didapatkan.

Seperti ditunjukkan pada Gambar 8, sebagian besar peserta atau sebanyak 58.3\% menyatakan bahwa mereka mendapatkan cukup banyak pengetahuan dari pelatihan TOEFL yang mereka ikuti, dan 33.3\% mengaku memperoleh banyak sekali pengetahuan yang mereka dapatkan. 


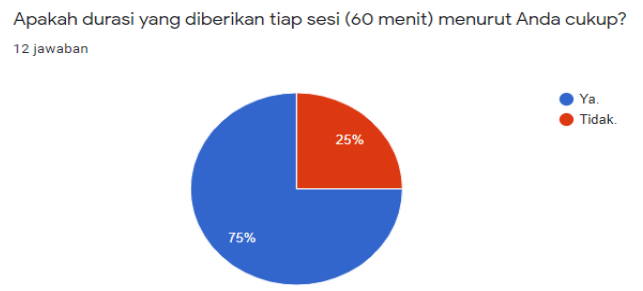

Gambar 9. Respon peserta tentang durasi pelatihan.

Gambar 9 menunjukkan bahwa 75\% peserta menyatakan durasi yang diberikan pada tiap sesi yaitu 60 menit cukup, sedangkan sisanya atau sebanyak $25 \%$ peserta menyatakan bahwa durasi tersebut tidak cukup. Pernyataan sebagian besar peserta yang menilai bahwa durasi 60 menit cukup untuk pelatihan bisa dikarenakan karena mode pelatihan yang diselenggarakan secara virtual, sehingga apabila melebihi durasi tersebut peserta berpotensi untuk merasa jenuh. Selain durasi, peserta juga diminta memberikan penilaian terhadap jumlah sesi pelatihan seperti ditunjukkan pada gambar di bawah ini.

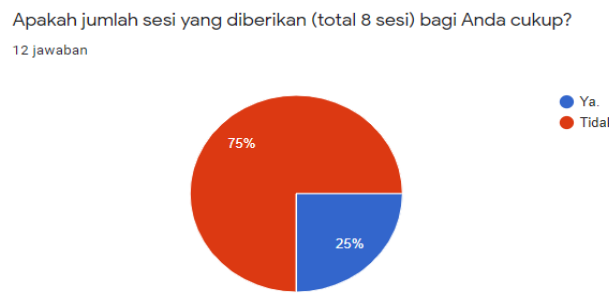

Gambar 10. Respon peserta terhadap jumlah sesi pelatihan.

Berdasarkan data yang ditunjukkan pada Gambar 10, sebagian besar peserta atau sebanyak $75 \%$ menilai bahwa jumlah sesi yaitu sebanyak 8 kali tidak cukup bagi mereka. Hal ini bisa dipahami mengingat materi dalam TOEFL mencakup banyak skill yang mestinya harus dipelajari semuanya. Pertanyaan berikutnya yaitu mengenai cara instruktur dalam menyampaikan materi.

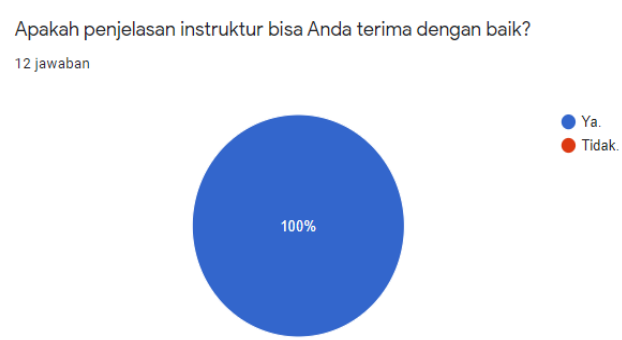

Gambar 11. Respon peserta terhadap penjelasan instruktur.

Gambar 11 mengungkap fakta yang menggembirakan karena seluruh peserta menyatakan bahwa penjelasan instruktur dalam menyampaikan materi bisa diterima dengan baik. Senada dengan hal tersebut, penilaian diri peserta terhadap kemampuan mereka dalam memahami atau menyerap materi juga diungkap dalam gambar di bawah ini.

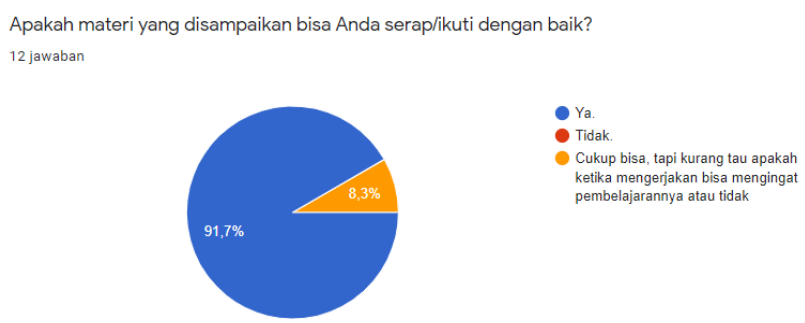

Gambar 12. Kemampuan peserta dalam menyerap materi yang disampaikan.

Gambar 12 mengungkap sebanyak $91.7 \%$ peserta mengaku bahwa mereka bisa memahami atau menyerap materi yang disampaikan selama pelatihan. Hal positif lainnya yaitu meningkatnya kepercayaan diri 
peserta terhadap tes TOEFL setelah mereka mengikuti pelatihan tersebut seperti ditunjukkan dalam gambar berikut.

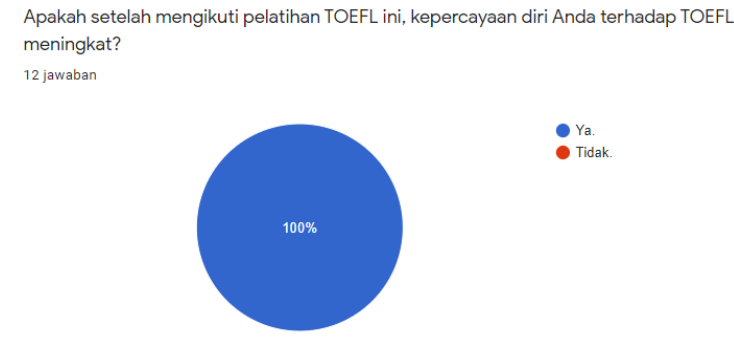

Gambar 13. Kepercayaan diri peserta setelah mengikuti pelatihan.

Seperti ditunjukkan pada Gambar 13, seluruh peserta (100\%) mengaku bahwa setelah mengikuti pelatihan TOEFL kepercayaan diri mereka terhadap TOEFL meningkat. Kepercayaan diri yang meningkat setelah mengikuti pelatihan TOEFL juga ditemukan pada kegiatan yang dilakukan oleh [14]. Ini menandakan bahwa pelatihan TOEFL yang mereka ikuti telah membuat mereka menjadi lebih mengerti tentang materi dan bentuk-bentuk soal dalam TOEFL.

\section{KESIMPULAN}

Berdasarkan data dari hasil evaluasi kegiatan, maka pelatihan TOEFL bagi para anggota Nasyiatul 'Aisyiyah Cabang Manterijeron Yogyakarta telah meningkatkan pengetahuan dan wawasan mereka tentang jenis-jenis soal TOEFL dan strategi-strategi untuk menjawabnya. Kepercayaan diri para peserta yang meningkat (seperti ditunjukkan di Gambar 13) setelah mengikuti pelatihan diharapkan membuat mereka lebih siap dan kompeten dalam menghadapi tes TOEFL yang akan mereka tempuh untuk menyelesaikan studi, melamar pekerjaan, menaikkan jabatan, maupun melanjutkan studi ke jenjang yang lebih tinggi.

\section{DAFTAR PUSTAKA}

[1] T. Pujiani, K. Nisa, and M. Soali, "Pelatihan TOEFL online melalui media Youtube untuk santri Pondok Pesantren Darussalam Purwokerto," Al-Mu'awanah J. Pengabdi. Kpd. Masy., vol. 1, no. 2, pp. 16-22, 2020.

[2] L. Syafii and A. Sugianto, "Pelatihan bahasa Inggris berekuivalensi TOEFL bagi dosen Universitas Muhammadiyah Ponorogo," Adimas J. Pengabdi. Kpd. Masy., vol. 1, no. 1, p. 25, 2017, doi: 10.24269/adi.v1i1.414.

[3] T. N. Fitria and I. E. Prastiwi, "Pelatihan tes Toefl (Test of English Foreign Language) untuk siswa SMK/SMA, mahasiswa, dosen dan umum," J. Budimas, vol. 02, no. 02, pp. 43-49, 2020.

[4] G. E. Putrawan and R. Deviyanti, "Pelatihan bahasa Inggris TOEFL-like test bagi siswa SMAN 4 Bandar Lampung," Sakai Sabayan J. Pengabdi. Masy., vol. 1, no. 3, pp. 122-128, 2018.

[5] D. Kartikawati, A. Fitrianingtyas, and W. I. Frisdinana, "Peningkatan kemampuan TOEFL bagi guru-guru SMA di Kabupaten Tulungagung," J-ADIMAS (Jurnal Pengabdi. Kpd. Masyarakat), vol. 2, no. 1, pp. 10-13, 2018.

[6] M. Saftari and Sinta, "Listening TOEFL training dan listening TOEFL test bidang bahasa Inggris di SMK Sore Pangkalpinang," J. Abdimastek, vol. 1, no. 1, pp. 14-20, 2020.

[7] G. Hasriani, R. Risan, and M. Nasta, "Pelatihan TOEFL bagi Lembaga MAMMESA," in Prosiding Seminar Nasional LPPM Universitas Negeri Makassar, 2019, pp. 238-240.

[8] M. A. Musi and Parwoto, "Pelatihan pengembangan program kemitraan PAUD di tengah pandemi Covid - 19," PENGABDI J. Has. Pengabdi. Masy. Vol.1, No.2 Pelatih., vol. 1, no. 2, pp. 75-82, 2020.

[9] S. Dhawan, "Online learning: a panacea in the time of COVID-19 crisis," J. Educ. Technol. Syst., vol. 0, no. 0, pp. 1-18, 2020, doi: 10.1177/0047239520934018.

[10] B. L. Moorhouse, "Adaptations to a face-to-face initial teacher education course 'forced' online due to the COVID-19 pandemic,” J. Educ. Teach., vol. 00, no. 00, pp. 1-3, 2020, doi: 10.1080/02607476.2020.1755205.

[11] A. B. Smoyer, K. O’Brien, and E. Rodriguez-Keyes, "Lessons learned from COVID-19: Being known in online social work classrooms," Int. Soc. Work, vol. 0, no. 0, pp. 1-4, 2020, doi: 10.1177/0020872820940021.

[12] R. Wong, "When no one can go to school: Does online learning meet students' basic learning needs?," Interact. Learn. Environ., vol. 0, no. 0, pp. 1-17, 2020, doi: 10.1080/10494820.2020.1789672.

[13] D. Phillips, Longman complete course for the TOEFL test: Preparation for the computer and paper tests. New York: Longman Pearson Education, 2001.

[14] A. Sudirman, "Peningkatan kompetensi bahasa Inggris bagi dosen-dosen Unma Banten melalui pelatihan " TOEFL Strategies and Predictions ,"” J. Pengabdi. pada Masy., vol. 5, no. 1, pp. 271-278, 2020.

[15] A. E. P. Atmojo and A. Nugroho, "EFL classes must go online! Teaching activities and challenges during COVID-19 pandemic in Indonesia," Regist. J., vol. 13, no. 1, pp. 49-76, 2020, doi: 10.18326/rgt.v13i1.49-76.

[16] E. T. Baloran, "Knowledge, attitudes, anxiety, and coping strategies of students during COVID-19 pandemic," $J$. Loss Trauma, vol. 0, no. 0, pp. 1-8, 2020, doi: 10.1080/15325024.2020.1769300. 
